\title{
Low-Dose Steroid after Thymectomy in Myasthenia Gravis: Is It a Complete Solution for Postoperative Respiratory Insufficiency?
}

\author{
Emre Erbabacan $^{a}$ Guniz M. Koksal ${ }^{a}$ Antonio M. Esquinas ${ }^{b}$ \\ ${ }^{a}$ Department of Anesthesiology and Reanimation, Cerrahpasa Medical Faculty, Istanbul University, Istanbul, Turkey; \\ ${ }^{\mathrm{b}}$ Intensive Care Unit, Hospital Morales Meseguer, Murcia, Spain
}

Dear Sir,

Postoperative respiratory insufficiency after thymectomy in Myasthenia gravis (MG) is a critical condition [1]. Currently, preventive strategies like the use of preoperative steroids after thymectomy show controversial results [2].

We have read the study done by Katao$\mathrm{ka}$ et al. with great interest where they have suggested that low-dose steroid treatment can prevent postoperative respiratory insufficiency (PRI) in patients with MG. However, we would like to refer to some questions and comments on the subject [3].

First, regarding the regimen of steroid in the postoperative period, two most important questions prevail: (a) Was the steroid dose lowered in the postoperative period? (b) How can the authors explain its mechanism of action? In addition, a dose of $30 \mathrm{mg} /$ day prednisolone is not a low dose steroid therapy [4]. Instead of using the term 'low-dose,' 'supraphysiological dose' could be used. Furthermore, it would be more noteworthy if the cortisol levels of patients were also reported.

Second, surgical technique is an important aspect that needs consideration, because it does not have the same effect on all the patients [3]. This may result in complex pathways, as steroid requirement can differ with different surgery techniques, resulting in the impairment of the standardization and influence rate of postoperative insufficiency.

Third, preoperative physostigmine doses used and preoperative respiratory function tests are related directly to the PRI in Myasthenia Gravis patients. Reporting of this data is also needed to evaluate PRI thoroughly.

Fourth, another important data that is directly related to PRI is the anesthesia technique and anesthetic agents used because of the influence they can have on the rate of postoperative respiratory insufficiency [5]. We believe two points need explanation: (a) More detailed information should be given about the anesthetic technique used, narcotics and neuromuscular blocking agents and their doses. Also the neuromuscular monitorization should be described [3]. (b) In the result section, it is stated that the use of epidural anesthesia did not differ in both groups, whereas the use of epidural anesthesia is not mentioned in the methods section [5]. More details should also be provided on epidural use, not only during the surgery but also during the surgery and in the postoperative period; epidural use only in the postoperative period for pain treatment could influence the results reported. Information on the level of catheter insertion, the use of agents and their doses given from the epidural catheter and the level of analgesia should be expressed. These determinants are well known that in myasthenia gravis patients, lower doses of local anesthetics or only opioids should be used to decrease respiratory compromise [5].

Finally, data about PRI and invasive or noninvasive ventilatory options could make the study interesting to make a proper extrapolation of these results. A more precise definition of PRI and the criteria used to acknowledge an unsuccessful extubation, rescue therapy with noninvasive mechanical ventilation and How many patients needed invasive mechanical ventilation.

We consider that it is important to know these determinants in this study in order to carry out a proper assessment of the impact of preoperative low-dose steroid in the prevention of PRI. Further prospective randomized trials need to confirm these results.

\section{Disclosure Statement}

The authors report no conflicts of interest related to our paper.
KARGER 125

(c) 2015 S. Karger AG, Base

0014-3022/15/0734-0193\$39.50/0
Emre Erbabacan, MD

Department of Anesthesiology and Reanimation, Istanbul University Cerrahpasa Medical Faculty, Kocamustafapasa, Fatih TR-34404 Istanbul (Turkey)

E-Mail emreerbabacan@ hotmail.com 


\section{References}

1 Zieliński M, Kuzdzał J, Staniec B, Harazda M, Nabiałek T, Pankowski J, Szlubowski A, Medoń J: Safety for preoperative use of steroids for transsternal thymectomy in myasthenia gravis. Eur J Cardiothorac Surg 2004; 26:407-411.

-2 Huang CS, Hsu HS, Huang BS, Lee HC, Kao KP, Hsu WH, Huang MH: Factors influencing the outcome of transsternal thymectomy for myasthenia gravis. Acta Neurol Scand 2005;112:108-114.
3 Kataoka H, Kiriyama T, Kawaguchi T, Sawa N, Sugie K, Horikawa H, Tojo T, Ueno S: Preoperative low-dose steroid can prevent respiratory insufficiency after thymectomy in generalized myasthenia gravis. Eur Neurol 2014; 72:228-233.
4 Saag KG, Koehnke R, Caldwell JR, Brasington R, Burmeister LF, Zimmerman B, Kohler JA, Furst DE: Low dose long-term corticosteroid therapy in rheumatoid arthritis: an analysis of serious adverse events. Am J Med 1994;96: 115-123.

5 Sungur Ulke Z, Yavru A, Camci E, Ozkan B, Toker A, Senturk M: Rocuronium and sugammadex in patients with myasthenia gravis undergoing thymectomy. Acta Anaesthesiol Scand 2013;57:745-748. 